\title{
Problem solving programme implemented by teachers may prevent depression in the short term, but longer term benefits are unclear
}

\author{
Spence SH, Sheffield JK, Donovan CL. Preventing adolescent depression. An evaluation of the Problem Solving for Life \\ program. J Consult Clin Psychology 2003 Feb;71:3-13.
}

\section{QUESTION: Can a teacher-led intervention prevent depression among non-referred adolescents?}

\section{Design}

Randomised controlled trial, with allocation by school unit. Schools were matched in pairs on the basis of state versus private funding and number of students enrolled. After paired matching, one school from each pair was assigned to the intervention group and the other to the control group.

Source of funding:

not specified.

For correspondence:

SH Spence, University

of Queensland, School

of Psychology, Brisbane,

Queensland, Australia.

\section{Setting}

11 state run and 5 private co-educational high schools in the Brisbane region of Queensland, Australia; timeframe not specified.

\section{COMMENTARY}

This is a methodologically exemplary trial of a population-based (universal) approach to preventing depression in young people. The programme used teachers in a classroom setting to deliver cognitive behavioural problem solving skills to a cohort of students.

We have little knowledge about "best practice" to prevent depression in adolescence. Classroom-based universal approaches appear to offer advantages in recruitment rates and lack of stigmatisation over approaches that target specific groups of at risk students. Earlier research on a universal school-based approach to preventing depression in adolescents showed promise, but employed mental health professionals to teach cognitive behavioural coping skills in small groups. ${ }^{1}$ Using such an approach routinely would be economically unsustainable. Spence's trial, with teachers as facilitators, therefore represents a "real world" intervention that could be routinely disseminated.

At first glance the results seem disappointing, as the prevention effect did not hold at follow up. Other trials using mental health professionals had more enduring effects on both general students and those at risk of depression. ${ }^{12}$ Based on findings from the current study, Andrews et al suggest that teachers are not appropriate to deliver preventative cognitive behavioural coping skills, arguing instead that computer-based delivery of cognitive skills may be the answer. ${ }^{3}$ This conclusion is premature. There may be other factors involved. For instance, in Spence's study teachers delivered the programme in large classes (estimated at 25-35 students) rather than the smaller groups in other trials. Nevertheless, with minimal training, teachers produced clinically significant effects on depression at post-intervention for both at risk and lower risk students.

Further research is needed into the conditions under which teachers may be more effective in delivering universal depression prevention programmes. With improved teacher selection and training, smaller groups and regular booster sessions, teachers may provide a more enduring effect. We may also need a different content and process to harness the important relationship between teachers and students. School-based universal prevention may be a pragmatic and non-stigmatising approach to preventing depression in young people. We need to work out the best use of teachers in this regard. Ian M Shochet, PhD School of Applied Psychology Griffith University Brisbane, Australia

1 Shochet IM, Dadds MR, Holland D et al. The efficacy of a universal school-based program to prevent adolescent depression. I Clin Child Psychology 2001:30:303-15.

2 Clarke GN, Hawkins W, Murphy M et al. Targeted prevention of unipolar depressive disorder in an at-risk sample of high school adolescents: A randomised trial of a group cognider in an at-risk sample of high school adolescents: A randomised
tive intervention. I Am Ac Child Adol Psychiatry 1995;34:312-21.

3 Andrews G, Szabo M, Burns J. Preventing major depression in young people. Brit J Psychiatry 2002;181:460-2.

\section{Participants}

1,500 students aged $12-14$ years (mean 13 years). 52\% were female. Students with scores of 13 or above on the Beck Depression Inventory at baseline were categorised as being at "high risk" of developing depression. Students whose Beck Depression Inventory scores were less than 13 were categorised as "low risk."

\section{Intervention}

The Problem Solving for Life programme was implemented by 28 teachers in 8 schools (751 students). The programme teaches young people to identify thoughts, feelings, and problem situations. It also teaches problem solving skills, including positive problem solving orientation. Teachers in the intervention group attended 6 hours of training on the theory underlying the programme, content, and implementation techniques. The programme comprised 8 weekly self contained sessions, lasting one class period of 45-50 minutes. Teachers were provided with curriculum materials designed to teach problem solving skills, positive problem solving orientation, and optimistic thinking styles. Teaching methods included didactic sessions; cartoons; individual, small group, and class exercises; homework; and diary keeping. Students and teachers at control schools received no intervention.

\section{Main outcome measures}

Depressive symptoms were assessed using the Beck Depression Inventory. Four questions were developed to measure dysthymia according to DSM-IV criteria. The Youth Self-Report form of the Child Behavior Checklist was used to measure general psychopathology. The Child and Adolescent Social and Adaptive Functioning Scale was used to assess social functioning and the Social Problem Solving Inventory - Revised Short Form was used to measure problem solving.

\section{Main results}

At the end of the intervention period, high risk students who received the programme had a greater decrease in depressive symptoms and increase in problem solving scores compared with high risk controls. Among low risk students, depression scores were slightly reduced and problem solving skills increased over the intervention period compared with low risk controls. Benefits were not maintained at 12-month follow up.

\section{Conclusions}

In the short term, this 8-week programme reduced symptoms of depression and increased problem solving skills among students at high and low risk of depression. There was no difference between groups after 1 year. 